ISSN = 1980-993X - doi:10.4136/1980-993X
www.ambi-agua.net
E-mail: ambi-agua@agro.unitau.br
Tel.: (12) 3625-4212

\title{
Avaliação da qualidade sanitária da alface (Lactuca sativa, L.) irrigada com água de reúso comparada com amostras comercializadas
}

\author{
(http://dx.doi.org/10.4136/ambi-agua.201) \\ Antonio Claudio Testa Varallo; Joseane Marioto de Souza ${ }^{2}$; Simone Sano Rossi Rezende ${ }^{3}$; \\ Claudinei Fonseca Souza ${ }^{4}$ \\ ${ }^{1}$ Professor Mestre, Departamento de Engenharia Civil - UNITAU; e-mail: antonio.varallo@yahoo.com.br \\ ${ }^{2}$ Engenheira Ambiental e Sanitarista; e-mail: joseanemarioto@hotmail.com \\ ${ }^{3}$ Técnica em química; e-mail: simonesrezende@hotmail.com \\ ${ }^{4}$ Professor Adjunto, Departamento de Recursos Naturais e Proteção Ambiental - CCA/UFSCar. \\ e-mail: cfsouza@cca.ufscar.br
}

\section{RESUMO}

O uso inadequado dos recursos hídricos reduz sua disponibilidade e, portanto, pesquisas para a reutilização da água são necessárias. O presente trabalho teve como objetivo avaliar comparativamente a qualidade sanitária da alface irrigada com água de reúso e da alface rotineiramente comercializada no município de Taubaté (SP). Foi desenvolvido um experimento em uma estufa que contou com três canteiros irrigados com água de reúso e três irrigados com água de abastecimento. Após completar o ciclo, as amostras foram analisadas em laboratório, assim como as amostras adquiridas no comércio. As análises foram realizadas usando a metodologia de tubos múltiplos. Os resultados demonstraram que nos canteiros irrigados com água de abastecimento não ocorreram contaminações por coliformes totais e termotolerantes, e nos irrigados com água de reúso não ocorreram contaminação por coliformes termotolerantes, apenas coliformes totais. Já as amostras comercializadas apresentaram contaminação tanto por coliformes totais como termotolerantes. Conclui-se que a aplicação da água de reúso para fins agrícolas deve ser tratada de maneira criteriosa de modo a viabilizar e contribuir para a sua sustentabilidade.

Palavras-chave: água de reúso; irrigação; coliformes; alface (Lactuca sativa, L.).

\section{Evaluation of sanitary quality of lettuce (Lactuca sativa, L.) irrigated with reused water in comparison with commercialized lettuce}

\section{ABSTRACT}

Inadequate use of water resources reduces their availability and therefore, research focused on their reutilization is required. This work evaluated the sanitary quality of lettuce irrigated with reused water in comparison with samples of lettuce commercialized in Taubaté (SP) market. An experiment was developed in a greenhouse with three beds of lettuce irrigated with reused water and three beds of lettuce irrigated with urban water supply. After lettuce biological cycle had been completed, lettuce samples were collected from the beds (irrigated and non-irrigated with reused water) and from samples of lettuce commercialized in the city market that were analyzed in the laboratory. The analyses were done using the multiple tubes methodology. The results showed that the samples from lettuce irrigated with urban water supply were not contaminated by either total or thermotolerant coliforms while samples of irrigated lettuce with reused water were contaminated by total coliforms. Samples from commercialized lettuce were contaminated by both kinds of coliforms. Results indicated 
VARALLO, A. C. T.; SOUZA, J. M. de; REZENDE, S. S. R.; SOUZA, C. F. Avaliação da qualidade sanitária da alface (Lactuca sativa, L.) irrigada com água de reúso comparada com amostras comercializadas AmbiAgua, Taubaté, v. 6, n. 2, p. 295-304, 2011. (doi:10.4136/ambi-agua.201)

that the application of reused water for agricultural purposes should occur only after carefully treatment to allow a safe use and to contribute to the water use sustainability.

Keywords: reuse water; irrigation; coliforms; lettuce (Lactuca sativa, L.).

\section{INTRODUÇÃO}

As hortaliças de um modo geral são essenciais e fazem parte da dieta alimentar de boa parte da população mundial. Normalmente são consumidas de forma "in natura" e, sem lavagem e controle sanitário adequados, servem como transmissores de micro-organismos patogênicos causadores de doenças (Itohan et al., 2011).

Dentre essas hortaliças, a alface (Lactuca sativa, L.) é a mais consumida no Brasil (Moretti e Mattos, 2005). Grande parte da sua produção encontra-se próxima às áreas metropolitanas devido ao curto período de vida pós-colheita (Hens e Suinaga, 2009). Nesses chamados "cinturões verde", é comum o uso de água com baixa qualidade para a irrigação, tendo em vista a contaminação das águas por efluentes municipais não tratados. Salem et al., (2011) afirmam que a disponibilidade hídrica em vários países está se tornando crítica, e uma das formas encontrada para suprir a necessidade agrícola é a utilização de águas resíduárias.

Fonseca et al. (2007) sugerem o uso de efluente de tratamento de esgoto para substituir com eficiência as águas de rios e córregos normalmente utilizadas na irrigação; porém recomendam monitoramento e estudos sobre o assunto, tendo em vista as implicações ambientais e sanitárias que possam gerar.

Conforme Marouelli e Silva (1998), é frequente a ocorrência de micro-organismos patogênicos, como E. coli, Salmonella sp e formas evolutivas de parasitos humanos em hortaliças e frutas consumidas "in natura" pela população. Baumgartner et al. (2007) afirmam ter uma preocupação de contaminação por organismos patogênicos em hortaliças irrigadas com águas residuárias.

Tresseler et al. (2009), avaliando a qualidade microbiológica em hortaliças minimamente processadas, detectaram a presença de Salmonella sp/25g em algumas amostras, tornando-as impróprias para o consumo humano.

Santos et al. (2010), ao estudarem a qualidade higiênico-sanitária de hortaliças e águas de irrigação em Salvador-BA, revelaram as condições precárias das áreas pesquisadas e o grande número de vegetais, bem como a água utilizada para a irrigação desses, que apresentaram contaminação por coliformes termotolerantes e E.coli.

Guimarães et al., (2003) encontraram baixos padrões higiênicos em amostras de alface (Lactuca sativa, L.) comercializadas em Lavras (MG), indicados pela presença de formas parasitológicas de origem animal ou humana e alta concentração de coliformes fecais. De acordo com Itohan et al. (2011), contaminações bacteriológicas em hortaliças, principalmente a alface, podem ser atribuída ao tamanho da superfície foliar suscetível ao contato de água de baixa qualidade sanitária usada na irrigação. A Organização Mundial de Saúde (WHO, 2006) recomenda como indicador da contaminação por patógenos do trato intestinal de animais/humanos a presença do E.coli.

Silva et al. (2006) afirmam que a presença de coliformes a $45^{\circ} \mathrm{C}$ não prova necessariamente a presença de contaminação de origem fecal. Sugerem que esse padrão seja reavaliado. Em sua pesquisa, $80 \%$ das amostras apresentaram contaminação por coliformes termotolerantes a $45^{\circ}$ e em $31 \%$ das amostras, a E. coli foi isolada.

O Ministério da Saúde, por meio da RDC n.12 de 02/01/2001 (ANVISA, 2001), que regula os padrões microbiológicos para alimentos, determina o valor máximo de $500 \mathrm{NMP} \mathrm{g}^{-1}$ para a presença de coliformes a $45^{\circ} \mathrm{C}$ e ausência de Salmonella sp $/ 25 \mathrm{~g}$. A mesma resolução denomina coliforme a $45^{\circ} \mathrm{C}$ equivalente a coliformes termotolerantes. 
VARALLO, A. C. T.; SOUZA, J. M. de; REZENDE, S. S. R.; SOUZA, C. F. Avaliação da qualidade sanitária da alface (Lactuca sativa, L.) irrigada com água de reúso comparada com amostras comercializadas AmbiAgua, Taubaté, v. 6, n. 2, p. 295-304, 2011. (doi:10.4136/ambi-agua.201)

O presente trabalho teve como objetivo verificar, segundo os padrões microbiológicos para coliformes termotolerantes da RDC $\mathrm{n}^{0} 12$ de 02/01/2001, a qualidade sanitária de amostras de alface (Lactuca sativa, L.) comercializadas em 3 hipermercados e 3 pontos de venda no Mercado Municipal na cidade de Taubaté (SP); e compará-los com amostras do produtor rural que forneceu para esse comércio especificamente, bem como com amostras de um experimento onde foi utilizado água de reúso na irrigação.

\section{MATERIAL E MÉTODOS}

Para o desenvolvimento deste trabalho foram realizadas análises comparativas da qualidade sanitária de alfaces (Lactuca sativa, L.), utilizando-se como indicativo de contaminação a presença de coliformes a $45^{\circ} \mathrm{C}$, conforme padrão de tolerância máxima permitida pela RDC n.12 de 02/01/2001 (ANVISA, 2001). Essas amostras foram coletadas em um experimento de campo onde se utilizou água de reúso e água de abastecimento local, com outras amostras coletadas no comércio de Taubaté (SP), provenientes de 3 hipermercados, 3 pontos de venda do Mercado Municipal da cidade e do produtor rural que fornece para esses pontos comerciais

\subsection{Experimento de campo}

O experimento de campo foi realizado em uma casa de vegetação controlada, localizada no Departamento de Ciências Agrárias da Universidade de Taubaté - UNITAU, com Latitude de $23^{\circ} 01^{\prime} 55^{\prime}$ 'S e Longitude de $45^{\circ} 30^{\prime} 39^{\prime}$ 'W e elevação de $571 \mathrm{~m}$.

O plantio das mudas iniciou-se no mês de junho/2008. Três canteiros denominados testemunhos foram irrigados com água de abastecimento local (T1, T2 e T3) e três outros canteiros com água de reúso (R1, R2 e R3). Foram conduzidos dois ciclos da cultura, irrigados de acordo com o manejo da água no solo, em dias alternados. Foi utilizado um sistema de irrigação por gotejamento alimentado por um reservatório de $500 \mathrm{~L}$ para cada tipo de água. Os gotejadores utilizados foram do tipo labirinto da marca Plasto, modelo Tufftif, com vazão nominal de $4,0 \mathrm{~L} \mathrm{~h}^{-1}$.

A água de reúso utilizada era proveniente de cozinha e banheiros do local, captada de um sistema fossa-filtro composta de um tanque séptico seguido de um filtro anaeróbio. A água de abastecimento era proveniente de um poço próximo à casa de vegetação.

Após 45 dias do plantio do segundo ciclo, realizou-se a colheita das amostras, tomandose cuidado com a assepsia para não ocorrer contato das folhas com o solo. Assim, as amostras foram acondicionadas em sacos plásticos esterilizados e levadas para o laboratório de Análise de Águas e Efluentes Líquidos do Departamento de Engenharia Civil da UNITAU, onde foram determinados os índices de contaminação por coliformes a $45^{\circ} \mathrm{C}$.

\subsection{Coleta de amostras comercializadas no município de Taubaté-SP}

Em janeiro de 2009, foram coletadas amostras das alfaces comercializadas no município de Taubaté (SP). Foram escolhidos 3 hipermercados (H1, H2 e H3) e 3 pontos de venda no Mercado Municipal (M1, M2 e M3), sendo adquiridas 6 amostras em cada um desses locais acima citados. Também foram coletadas do produtor rural que forneceu para esses pontos comerciais 6 unidades de alface por canteiro, escolhidas aleatoriamente em 3 canteiros (P1, P2 e P3).

\subsection{Sistema de manejo e cultivo das hortaliças do produtor rural}

A área do produtor rural está localizada numa região próxima à cidade de Taubaté (SP), com afloramento do lençol freático, de onde é retirada a água para a irrigação das hortaliças. O sistema de irrigação utilizado é por aspersão. O volume de água necessária é captado por 
VARALLO, A. C. T.; SOUZA, J. M. de; REZENDE, S. S. R.; SOUZA, C. F. Avaliação da qualidade sanitária da alface (Lactuca sativa, L.) irrigada com água de reúso comparada com amostras comercializadas AmbiAgua, Taubaté, v. 6, n. 2, p. 295-304, 2011. (doi:10.4136/ambi-agua.201)

bomba e conduzido para um tanque de armazenamento onde, posteriormente, é feita a distribuição através de mangueiras.

Após completar o ciclo da cultura, as hortaliças são colhidas e levadas para um tanque de lavagem com água corrente, também proveniente do lençol freático aflorado. Após a lavagem, elas são embaladas em plásticos e levadas para comercialização.

\subsection{Determinação dos indicativos de contaminação por coliformes a $45^{\circ} \mathrm{C}$ em laboratório}

Nas águas utilizadas para irrigação do experimento de campo e do produtor rural, as análises para determinação de coliformes a $45^{\circ} \mathrm{C}$ seguiram a metodologia descrita por APHA (2000). Para determinação de coliformes a $45^{\circ} \mathrm{C}$ nas amostras das alfaces, a metodologia utilizada foi a descrita por Silva et al. (2007).

\section{RESULTADOS E DISCUSSÃO}

A Tabela 1 apresenta os valores médios comparativos da qualidade da água de abastecimento e reúso utilizados no experimento de campo, com a água do produtor rural e os valores recomendados por Ayers e Westcot (1994) para água de irrigação e USEPA (2004) para água de reúso utilizada na irrigação.

Fonseca et al. (2007), em estudos realizados no Brasil, encontraram valores de $\mathrm{pH}$ (7,2 e $7,5)$ em efluentes de esgotos tratados para a agricultura próximos aos valores da água de reúso utilizados no experimento de campo. Porém, para valores de STD $(528,0$ a $571,0 \mathrm{mgL}^{-1}$ ), os valores encontrados neste trabalho estão acima. Quando comparados aos estabelecidos por Ayers e Westcot (1994) e USEPA (2004), observa-se que estes estão dentro dos parâmetros permitidos.

Baumgartner et al., (2007), avaliando o desenvolvimento de produção e qualidade sanitária da alface irrigada com águas residuárias provenientes da suinocultura e da piscicultura com diversos tratamentos, encontraram valores de sódio $\left(7,3\right.$ a $\left.13,7 \mathrm{mmol}_{\mathrm{C}} \mathrm{L}^{-1}\right)$ superiores aos da água de reúso utilizada no experimento de campo. Nos dois trabalhos, esses valores estão acima dos recomendados por Ayers e Westcot (1994), indicando restrição de uso em relação à toxicidade de íons como o $\mathrm{Na}^{+}$. Sandri et al. (2007) encontraram valores sem restrição de uso para água residuária utilizando um sistema de leitos cultivados com macrófitas após um filtro anaeróbio. Porém, não foi eficiente na remoção dos coliformes totais e da E.coli. Os índices de coliformes totais encontrados na água de abastecimento e de reúso são maiores que o máximo permitido para uso na irrigação conforme afirmado por Marouelli e Silva (1998) e também encontrado por Sandri et al. (2007), indicando que eles não deveriam ultrapassar $5000 \mathrm{NMP} / 100 \mathrm{ml}$.

Baumgartner et al. (2007) encontraram coliformes totais com valores superiores a 5000 NMP/100ml em águas de efluentes de lagoas de estabilização de dejetos de suínos. Takayanagui et al. (2006) afirmam que a contaminação de hortaliças ocorrem, de modo geral na horta, por meio da utilização de água de irrigação ou adubos inadequados; além da manipulação nos pontos de venda e transporte dos produtos. Os valores encontrados nas águas de reúso, de abastecimento e do produtor rural apresentaram valores de coliformes totais e coliformes a $45^{\circ} \mathrm{C}$ que poderiam causar algum tipo de contaminação nas folhas de alface devido ao manejo da irrigação adotada. 
Tabela 1. Valores médios comparativos da qualidade da água de abastecimento e reúso do experimento de campo, com a água do produtor rural, e com os valores recomendados pela Ayers e Westcot (1994) para irrigação e USEPA (2004) para reúso na irrigação.

\begin{tabular}{l|ccccc}
\hline Parâmetros & $\begin{array}{c}\text { Água de } \\
\text { abastecimento }\end{array}$ & $\begin{array}{c}\text { Água } \\
\text { de } \\
\text { reuso }\end{array}$ & $\begin{array}{c}\text { Água do } \\
\text { produtor } \\
\text { rural }\end{array}$ & $\begin{array}{c}\text { Ayers e } \\
\text { Westcot } \\
\mathbf{( 1 9 9 4 )}\end{array}$ & $\begin{array}{c}\text { Valores } \\
\text { USEPA } \\
\text { (2004) }\end{array}$ \\
\hline $\mathrm{pH}$ & 7,8 & 7,2 & $\mathrm{Nr}^{* *}$ & $6 \mathrm{e} 8,5$ & $6-9$ \\
Dureza $\left(\mathrm{mg} \mathrm{L}^{-1}\right)$ & 66,12 & 94,90 & $\mathrm{Nr}^{* *}$ & ---- & ---- \\
Cloro $\left(\mathrm{mmol}_{\mathrm{c}} \mathrm{L}^{-1}\right)$ & 0,12 & 2,18 & $\mathrm{Nd}^{*}$ & $0-30$ & $<1$ \\
Turbidez & 0,90 & 15,00 & $\mathrm{Nr}^{* *}$ & ----- & $\leq 2$ \\
Nitrato $\left(\mathrm{mg} \mathrm{L}^{-1}\right)$ & 0,06 & 0,09 & $\mathrm{Nr}^{* *}$ & $0-10$ & ----- \\
Sódio $\left(\mathrm{mmol}_{\mathrm{c}} \mathrm{L}^{-1}\right)$ & 0,78 & 3,70 & $\mathrm{Nr}^{* *}$ & $0-3$ & ----- \\
Potássio $\left(\mathrm{mg} \mathrm{L}^{-1}\right)$ & 15,00 & 29,00 & $\mathrm{Nr}^{* *}$ & $0-2$ & ----- \\
CE $\left.(\mathrm{dS} \mathrm{m})^{-1}\right)$ & 0,21 & 0,99 & $\mathrm{Nr}^{* *}$ & $0-3$ & ---- \\
STD $\left(\mathrm{mg} \mathrm{L}^{-1}\right)$ & $1.173,6$ & $1.057,6$ & $\mathrm{Nr}^{* *}$ & $0-2000$ & $500-2000$ \\
RAS(mmol $\left.\mathrm{L}^{-1}\right)^{0,5}$ & 1,50 & 6,10 & $\mathrm{Nr}^{* *}$ & $0-15$ & ----- \\
ColiformesTotais & $\mathrm{Cc}{ }^{* * *}$ & 90.000 & 21 & ---- & ---- \\
(NMP/100ml) & & & & & \\
Coliformes a 45 & & & & & --- \\
(NMP/100ml) & $\mathbf{C c}^{* * *}$ & $\mathbf{5 0 0}$ & $\mathbf{2 1}$ & --- & --- \\
\hline
\end{tabular}

* Não detectado - ** Não realizado - *** Crescimento confluente

Mattos et al. (2009) afirmam que a contaminação microbiológica em hortaliças é devido ao uso de água contaminada para irrigação, enquanto que a contaminação química seria resultante da aplicação de defensivos agrícolas.

Santos et al. (2010) encontraram elevados índices de contaminação por coliformes a $45^{\circ} \mathrm{C}$ em 140 amostras de hortaliças e 45 amostras de água para irrigação. Dentre as hortaliças analisadas, a alface e o coentro foram os que apresentaram maior incidência de contaminação e, nas amostras de água de irrigação, 89\% apresentaram contaminação.

Ainda de acordo com Santos et al. (2010), vários estudos demostram que a água de irrigação é o principal causador de contaminação de vegetais na agricultura.

Takayanagui et al. (2006) detectaram a presença de coliformes a $45^{\circ} \mathrm{C}$ em $69 \%$ de cadeias de produção de verduras em Ribeirão Preto (SP); a água de irrigação apresentou irregularidades em $22 \%$ das amostras e em $38 \%$ das amostras utilizadas na lavagem das hortaliças.

De acordo com a RDC n.12 de 02/01/2001 (ANVISA, 2001), que estabelece os critérios de padrões microbiológicos sanitários em alimentos, a tolerância máxima para amostra seria de $500 \mathrm{NMP} \mathrm{g}^{-1}$ para coliformes a $45^{\circ} \mathrm{C}$.

A Tabela 2 mostra os resultados das análises bacteriológicas das alfaces irrigadas com água de reúso e água de abastecimento do experimento de campo, indicando que apenas em duas amostras foi detectada a presença de coliformes totais e ausência de coliformes a $45^{\circ} \mathrm{C}$ em todas as amostras 
VARALlO, A. C. T.; SOUZA, J. M. de; REZENDE, S. S. R.; SOUZA, C. F. Avaliação da qualidade sanitária da alface (Lactuca sativa, L.) irrigada com água de reúso comparada com amostras comercializadas AmbiAgua, Taubaté, v. 6, n. 2, p. 295-304, 2011. (doi:10.4136/ambi-agua.201)

Tabela 2. Resultados das análises bacteriológicas das alfaces irrigadas com água de reúso e água de abastecimento.

\begin{tabular}{|c|c|c|c|c|}
\hline Amostras & $\begin{array}{c}\text { Coliformes } \\
\text { Totais } \\
\left(\mathrm{NMP} \mathrm{g}^{-1}\right) \\
\end{array}$ & Resultado & $\begin{array}{c}\text { Coliformes } \\
\text { a } 45^{\circ} \mathrm{C} \\
\left(\mathrm{NMP} \mathrm{g}^{-1}\right) \\
\end{array}$ & Resultado \\
\hline $\mathbf{T 1}$ & $<3,0$ & Ausente & $<3,0$ & Ausente \\
\hline $\mathbf{T} 2$ & $<3,0$ & Ausente & $<3,0$ & Ausente \\
\hline T3 & $<3,0$ & Ausente & $<3,0$ & Ausente \\
\hline R1 & 15 & Presente & $<3,0$ & Ausente \\
\hline R2 & $<3,0$ & Ausente & $<3,0$ & Ausente \\
\hline R3 & $>1.100$ & Presente & $<3,0$ & Ausente \\
\hline
\end{tabular}

Apesar da não existência de padrões federais para níveis de coliformes totais em hortaliças, os índices de contaminação apresentaram-se elevados, demonstrando condições higiênicas deficientes. A utilização de coliformes como indicadores de condições higiênicas pode indicar que, uma alta contagem desses micro-organismos no alimento significaria uma possível contaminação durante a produção, limpezas e sanificações deficientes, ou até mesmo multiplicação desses, durante o processamento ou estocagem, conforme pesquisado por Takayanagui et al. (2001).

A Tabela 3 mostra os resultados das análises bacteriológicas das alfaces comercializadas no município de Taubaté (SP) e do produtor rural, indicando a presença de coliformes totais em todas as amostras e a presença de coliformes a $45^{\circ} \mathrm{C}$ em pelo menos uma amostra coletada no Mercado Municipal (M2), uma do hipermercado (H2) e uma de um canteiro do produtor rural (P3).

Tabela 3. Resultados bacteriológicos das alfaces comercializadas no município de Taubaté (SP).

\begin{tabular}{c|cc|cl}
\hline Amostras & $\begin{array}{c}\text { Coliformes } \\
\text { Totais } \\
\left.\text { (NMP g } \mathbf{~}^{-1}\right)\end{array}$ & Resultado & $\begin{array}{c}\text { Coliformes } \\
\text { a 45 } \mathbf{C} \\
\mathbf{N M P ~}^{-\mathbf{1}} \text { ) }\end{array}$ & Resultado \\
\hline M1 & $>1.100$ & Presente & $<3,0$ & Ausente \\
M2 & 290,0 & Presente & 3,6 & Presente \\
M3 & $>1.100$ & Presente & $<3,0$ & Ausente \\
H1 & $>1.100$ & Presente & $<3,0$ & Ausente \\
H2 & $>1.100$ & Presente & 3,6 & Presente \\
H3 & $>1.100$ & Presente & $<3,0$ & Ausente \\
P1 & 460,0 & Presente & $<3,0$ & Ausente \\
P2 & $>1.100$ & Presente & $<3,0$ & Ausente \\
P3 & $>1.100$ & Presente & 43,0 & Presente \\
\hline
\end{tabular}


VARALLO, A. C. T.; SOUZA, J. M. de; REZENDE, S. S. R.; SOUZA, C. F. Avaliação da qualidade sanitária da alface (Lactuca sativa, L.) irrigada com água de reúso comparada com amostras comercializadas AmbiAgua, Taubaté, v. 6, n. 2, p. 295-304, 2011. (doi:10.4136/ambi-agua.201)

Santana et al. (2006) consideram que o alto grau de contaminação de hortaliças é devido à baixa qualidade da água utilizada para abastecer o sistema de irrigação.

Pelo gráfico representativo da média dos índices de contaminação por coliformes a $45^{\circ} \mathrm{C}$ (Figura 1), observou-se que os níveis de contaminação encontrados nas alfaces comercializadas no município de Taubaté (SP) estão superiores aos encontrados na cultura desenvolvida no experimento de campo, principalmente a média das amostras do produtor rural.

De acordo com a RDC n.12 de 02/01/2001 (ANVISA, 2001), que determina o índice máximo de contaminação para consumo de verdura fresca "in natura", para coliformes a $45^{\circ} \mathrm{C}$, todas as amostras atendem ao padrão estipulado.

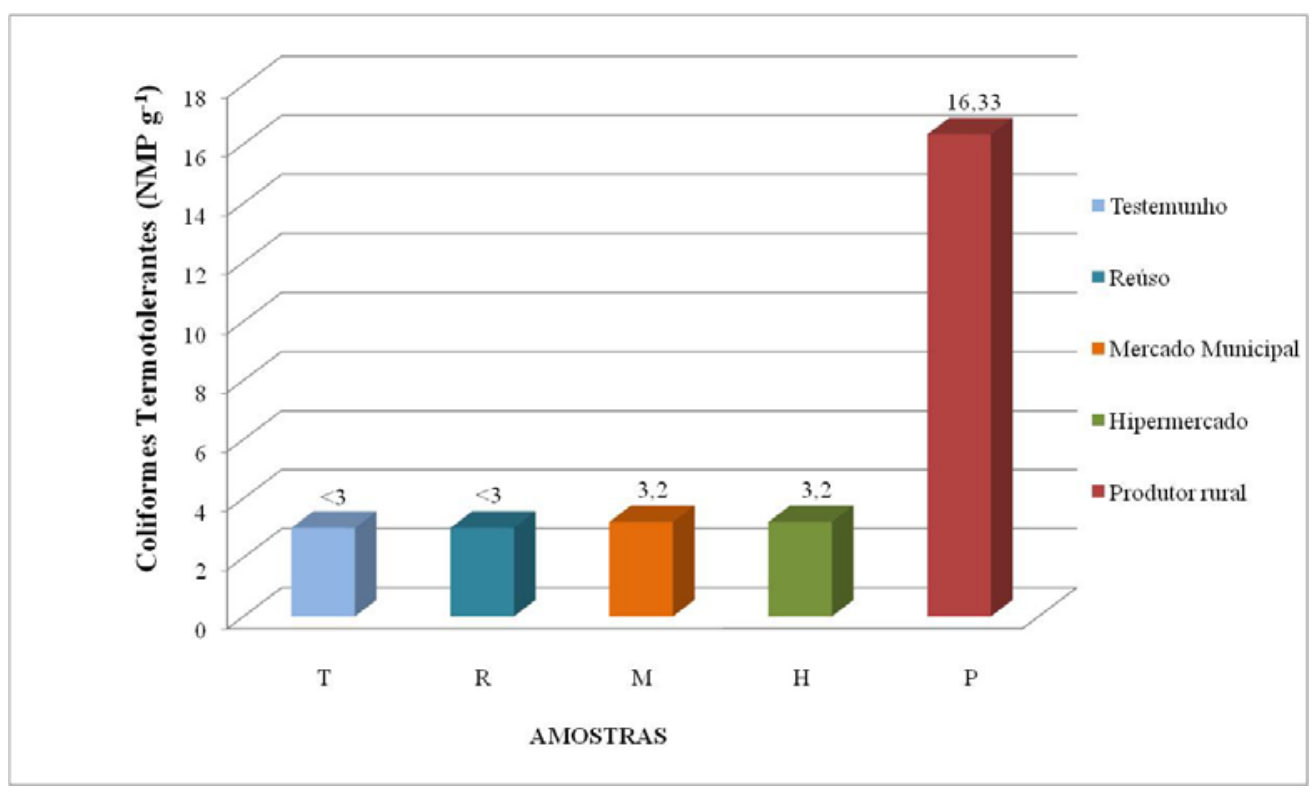

Figura 1. Média dos índices de contaminação por coliformes a $45^{\circ} \mathrm{C}$ expressos em NMP $g^{-1}$.

Guimarães et al. (2003) encontraram altas concentrações de coliformes fecais em amostras de alface comercializadas no município de Lavras (MG). Santana et al. (2006), analisando amostras de alfaces de cultivo orgânico tradicional e hidropônico, comercializados nos principais supermercados de Salvador (BA), detectaram a presença de formas parasitárias de origem humana e/ou animal, além de altas concentrações de coliforme total e coliformes a $45^{\circ} \mathrm{C}$, sugerindo a necessidade de medidas para melhorar a qualidade higiênico-sanitárias das hortaliças.

Machado et al. (2006), avaliando a qualidade microbiológica de hortaliças orgânicas produzidas com adubo mineral e estercos de animais variados, evidenciaram que todas as amostras foram consideradas apropriadas para o consumo humano, de acordo com a legislação brasileira em vigor, uma vez que nenhuma apresentou contaminação por Salmonella sp/25g. Porém, 63,3\% das amostras de alface apresentaram contagens de coliformes totais $\geq 100 / \mathrm{g}$ e, somente $6,6 \%$ apresentaram contagens de coliformes a $45^{\circ} \mathrm{C}>$ $100 / \mathrm{g}$. Em todas as amostras de alface não foram detectadas a presença de E. coli.

Abreu et al. (2010) observaram a contaminação da água de irrigação e da alface por coliformes a $45^{\circ} \mathrm{C}$ sob adubação orgânica e não detectaram contaminação por Salmonella $s p / 25 \mathrm{~g}$. Entretanto, de acordo com a legislação vigente, as alfaces colhidas no experimento seriam condenadas para consumo humano em função da contaminação por coliformes.

Segundo Silva et al. (2006), os coliformes a $45^{\circ} \mathrm{C}$ são os capazes de fermentar a lactose com produção de gás em $48 \mathrm{~h}$. A Escherichia coli, e algumas cepas de Enterobacter e 
Klebsiella também podem apresentar essas características. Porém, somente a E. coli indica presença de contaminação fecal por ser encontrada em grandes quantidades no trato gastrointestinal do homem e animais de sangue quente. Portanto, a presença de coliformes a $45^{\circ} \mathrm{C}$ não indicaria, necessariamente, contaminação de origem fecal.

Porém, Takayanagui et al. (2006) observaram em estudos algumas associações parasitárias como: Entamoeba sp e ancilostomídeos; Entamoeba sp e Giardia sp, Ascaris sp, Entamoeba sp e Isospora sp; Trichuris sp, Entamoeba sp e ancilostomídeos. Afirmam ainda que, Entamoeba sp e ancilostomídeos, nem sempre patogênicos ao homem, foram detectadas somente em concomitância a um valor igual ou superior a $200 \mathrm{NMP} \mathrm{g}^{-1}$ de coliformes a $45^{\circ} \mathrm{C}$. Sendo assim, a determinação de coliformes a $45^{\circ} \mathrm{C}$ constitui um importante indicador de condições higiênico-sanitárias deficientes na produção agrícola.

\section{CONCLUSÕES}

1. As alfaces irrigadas com água de reúso não apresentaram contaminação por coliformes a $45^{\circ} \mathrm{C}$ e, portanto, encontram-se dentro dos padrões da $\mathrm{RDC} \mathrm{n}^{\circ} 12 \mathrm{de}$ $02 / 01 / 2001$, para consumo humano, tendo como referência os coliformes a $45^{\circ} \mathrm{C}$;

2. Duas amostras das alfaces comercializadas no município de Taubaté-SP e uma do produtor rural apresentaram contaminação por coliformes a $45^{\circ} \mathrm{C}$, porém estão de acordo com os parâmetros estipulados pela legislação brasileira;

3. A falta de higiene durante o processo de manipulação e transporte pode ter causado a contaminação das amostras comercializadas por coliformes totais;

4. A determinação de coliformes a $45^{\circ} \mathrm{C}$ pode ser um importante indicador de condições higiênico-sanitárias deficientes e, pode determinar outras associações parasitárias prejudiciais ao homem.

\section{AGRADECIMENTOS}

Os autores agradecem à Fundação de Amparo à Pesquisa do Estado de São Paulo e à UNITAU pelos auxílios concedidos.

\section{REFERÊNCIAS}

ABREU, I. M. de O.; JUNQUEIRA, A. M. R.; PEIXOTO, J. R.; OLIVEIRA, S. A. Qualidade microbiológica e produtividade de alface sob adubação química e orgânica. Revista Ciência e Tecnologia de Alimentos, v. 30, p. 108-118, 2010. Suplemento 1.

AGÊNCIA NACIONAL DE VIGILÂNCIA SANITÁRIA - ANVISA (Brasil). Resolução RDC n.12, de 02 de janeiro de 2001. Diário Oficial [da] República Federativa do Brasil Brasília, DF, 10 fev. 2001. Seção 1, p. 45-53.

AMERICAN PUBLIC HEALTH ASSOCIATION - APHA. Standard methods for examination of water and wastewater. 20. ed. Washington, DC: APHA, 2000.

AYERS, R. S.; WESTCOT, D. W. Water quality for agriculture. In: FAO. Irrigation and drainage paper. 29. ed., 1. rev. New York, 1994.

BAUMGARTNER, D; SAMPAIO, S. C.; SILVA, T. R. da; TEO, C. R. P. A.; VILAS BOAS, M. A. Reúso de águas residuárias da piscicultura e da suinocultura na irrigação da cultura da alface. Revista de Engenharia Agrícola, v. 27, n.1, p. 152-163, 2007. 
FONSECA, A. F. da; HERPIN, U.; PAULA, A. M. de; VICTÓRIA, R. L.; MELFI, A. J. Agricultural use of treated sewage effluents: agronomic and environmental implications and perspectives for Brazil. Scientia Agricola Journal, v. 64, n. 2, p. 194-209, 2007. http://dx.doi.org/10.1590/S0103-90162007000200014

Guimarães, A. M.; AlveS, E. G. L.; Figueiredo, H. C. P.; COSTA, G. M.; RODRIGUES, L. S. Freqüência de enteroparasitas em amostras de alface (Lactuca sativa) comercializadas em Lavras, Minas Gerais. Revista Sociedade Brasileira de Medicina Tropical, v. 36, n. 5, p. 132-135, 2003.

HENS, G. P.; SUINAGA, F. Tipos de alface cultivados no Brasil. Brasília, DF: EMBRAPA, 2009. 7p. (Comunicado Técnico, n. 75)

ITOHAN, A. M.; PETERS, O.; KOLO, I. Bacterial contaminants of salad vegetables in Abuja Municipal Area Concil, Nigeria. Malaysian Journal of Microbiology, v. 7, n. 2, p. 111-114, 2011.

MACHADO, D. C.; MAIA, C. M.; CARVALHO, I. D.; SILVA, N. F. da; ANDRÉ, M. C. D. P. B.; SERAFINI, A. B. Microbiological quality of organic vegetables produced in soil treated with different types of manure and mineral fertilizer. Brazilian Journal of Microbiology, v. 37, p. 538-544, 2006. http://dx.doi.org/10.1590/S151783822006000400025

MAROUELli, W. A.; SILVA, H. R. da. Aspectos sanitários da água para fins de irrigação. Brasília, DF: EMBRAPA HORTALÍÇAS, 1998. 8p. (Comunicado Técnico, n. 5)

MATTOS, L. M.; MORETTI, C. L.; MOURA, M. A. de; MALDONADE, I. R.; SILVA, E. Y. Y. da. Produção segura e rastreabilidade de hortaliças. Horticultura Brasileira, v. 27, n. 4, p. 408-413, 2009.

MORETTI, C. L.; MATTOS, L. M. Processamento mínimo da alface crespa. Brasília, DF: EMBRAPA, 2005. 6p. (Comunicado Técnico, n. 25)

SALEM, I. B.; OUARDANI, I.; HASSINE, M.; AOUNI, M. Bacteriological and physicchemical assessment of wastewater in different region of Tunisia: impact on human health. BMC Research Notes, v. 4, n. 1, p. 144, 2011.

http://dx.doi.org/10.1186/1756-0500-4-144

SANDRI, D.; MATSURA, E. E.; TESTEZLAF, R. Desenvolvimento da alface Elisa em diferentes sistemas de irrigação com água residuária. Revista Brasileira de Engenharia Agrícola e Ambiental, v. 11, n. 1, p. 17-29, 2007.

SANTANA, L. R. R. de; CARVAlHO, R. D. S.; LEITE, C. C.; AlCANTARA, L. M.; OLIVEIRA, T. W. S. de; RODRIGUES, B. da M. Qualidade física, microbiológica e parasitológica de alfaces (Lactuca Sativa) de diferentes sistemas de cultivo. Revista Ciência e Tecnologia de Alimentos, v. 26, n. 2, p. 264-269, 2006.

SANTOS, Y. O.; ALMEIDA, R. C. de C.; GUIMARÃES, A. G.; ALMEIDA, P. F. Hygienicsanitary quality of vegetables and evaluation of treatments for the elimination of indigenous E. coli and E. coli O157:H7 from the surface of leaves of lettuce (Lactuca sativa L.). Revista Ciência e Tecnologia de Alimentos, v. 30, n. 4, p. 1083-1098, 2010. 
SILVA, M. P.; CAVALLI, D. R.; OLIVEIRA, T. C. R. M. Avaliação do padrão coliformes a $45^{\circ} \mathrm{C}$ e comparação da eficiência das técnicas dos tubos múltiplos e petrifilm EC na detecção de coliformes totais e Escherichia coli em alimentos. Revista Ciência e Tecnologia de Alimentos, Campinas, v. 26, n. 2, p. 352-359, 2006.

SILVA, N. da; JUNQUEIRA, V. C. A.; SILVEIRA, N. F. A.; TANIWAKI, M. H.; SANTOS, R. F. S. dos; GOMES, R. A. R. Manual de métodos de análise microbiológica de alimentos. 3. ed. São Paulo: Livraria Varela, 2007. p. 119-135.

TAKAYANAGUI, O. M.; OLIVEIRA, C. D.; BERGAMINI, A. M. M.; CAPUANO, D. M.; OKINO, M. H. T.; FEBRÔNIO, L. H. P. et al. Fiscalização de verduras comercializadas no município de Ribeirão Preto, SP. Revista Sociedade Brasileira de Medicina Tropical, v. 34, n. 1, p. 37-41, 2001.

TAKAYANAGUI, O. M.; CAPUANO, D. M.; OLIVEIRA, C. A. D.; BERGAMINI, A. M. M.; OKINO, M. H. T.; CASTRO e SILVA, A. A. M. C. et al. Análise da cadeia de produção de verduras em Ribeirão Preto (SP). Revista Sociedade Brasileira de Medicina Tropical, v. 39, n. 2, p. 224-226, 2006.

TRESSELER, J. F. M.; FIGUEIREDO, E. A. T. de; FIGUEIREDO, R. W. de; MACHADO, T. F.; DELFINO, C. M.; SOUZA, P. H. M. de; Avaliação da qualidade microbiológica de hortaliças minimamente processadas. Ciência e Agrotecnologia. v. 33, edição especial, p. 1722-1727, 2009.

ENVIRONMENTAL PROTECTION AGENCY - USEPA. (United States). Guidelines for water reuse. EPA/625/R-04/108. Washington, DC, Sept., 2004.

WORLD HEALTH ORGANIZATION - WHO. Global strategy for food safety: safer food for better health. [S.1.], 2006. (Food Issues) 